\title{
Importance of Search Engine Marketing in the Digital World
}

\author{
Arokia R. Terrance, Shruti Shrivastava, Asmita Kumari \\ Computer Science, Kalindi College, University of Delhi, India \\ \{arokia.ramyat,shruti110697,masmita36\}@gmail.com
}

\begin{abstract}
Object tracking is one of the vital fields of computer vision that detects the moving object from a video sequence. Internet has changed the world to global village. Due to improved connectivity and increase in data usage, any new or existing products or services can reach the consumer easily through digital marketing. Apart from creating a content rich website for a product, it is highly important that the website is at the top of the Search Engine Result Pages (SERPS) of a Search Engine. The technical aspect of Search Engine Marketing Management (SEMM) of the website can be substantially improved by carrying out Search Engine Optimization (SEO) analysis of the website. The SEO tool can be utilized for increasing the website traffic and consequently increasing the sales revenue. This paper focuses on the interlinkage of Search Engine Marketing and Search Engine Optimization. The paper also provides the impact of Keyword analysis and the other SEO friendly techniques that positively affects the digital marketing.
\end{abstract}

Index Terms-Search Engine Marketing Management, Search Engine Optimization, Search Engine Result Pages, SEO tools

\section{INTRODUCTION}

$\mathrm{I}$ NTERNET marketing refers to the process of promoting the products or services among the internet users through social media, search engine, banner ads on specific websites, email and app development. It helps to increase the amount and quality of sales leads of desired products or services. Search Engine Marketing (SEM) is the set of activities that involves Search Engine Optimization (SEO), Social Media Marketing (SMM) and other search engine related functions. Search Engine Marketing Management (SEMM) integrates marketing management process that promotes the position of the website's products or services towards the beginning of the search result in SERP which in turn increase its business. [5] SEM relates to the inclusion of all SEO activities but focus on return on investment (ROI), instead of relevant traffic building. SEM also integrates organic SEO and paid SEO. Social Media Marketing uses one or several social media channels to engage with customers, build relationships and then sell our products or services.

\section{Comparison Study of SEM AND SeO}

SEO is defined as the process of improving visibility and improving ranking of website in search engine result page .In general, high ranked sites on SERP appears more fre- quently in search result list and therefore receive more traffic from search engine user. This traffic or visitors can then be converted into customers. The SEO can be achieved by either organic SEO or paid SEO. Through organic SEO, website owner adjudicates to achieve top ranking for the website in the search result without using any paid means to achieve it. Through paid SEO or paid advertising using Google Adwords, website owner buys an advertising space in search engine result in order to achieve top ranking for the website in the search result and not to get more traffic. [4]

In order to understand SEO, we need to know the working of search engine that involves four major activities namely Web Crawling where the crawler search for text and hyperlinks that moves from one web page to another webpage, Build Indexing where the index about keyword and their location of the crawled webpages were created, Calculate Relevancy where the degree of relevancy between content and searcher's query were calculated, Result Retrieving where the decision upon the order of pages in the search engine result were taken. [3]

SEM is the marketing process with a goal of obtaining more visibility in search engines either by getting more free traffic or paid traffic. SEM incorporates Search Engine Optimization (SEO), which adjusts or rewrites the website content and site architecture in order to achieve higher page ranking in search engine result pages and enhance pay per click (PPC) listings. To generate best results, both organic SEO and paid SEO practices must have shared goals and combined metrics, evaluated the data to determine future strategy or find out right tools to get traffic for selected keywords in national and local search results. [1] The SEO tools can help Search Engine Marketing (SEM) through the overall improvement of landing pages by technical auditing the web pages of a website. It helps to improve code and schema, eliminates poor-quality links and highlight any other areas of potential improvement which in turn helps to increase the performance, gain more traffic and conversions to the site. The comparison study of SEO and SEM is tabulated in the below table 1 .

\section{Keyword Analysis}

The keyword analysis is one of the most important, valuable and high position activity in Search Engine Marketing 
Table 1: Comparison of SEO and SEM

\begin{tabular}{|l|l|l|}
\hline FEatures & $\begin{array}{l}\text { Organic SEO and } \\
\text { Paid SEO }\end{array}$ & $\begin{array}{l}\text { Integration of SEO } \\
\text { with SMO }\end{array}$ \\
\hline Focus & $\begin{array}{l}\text { Keywords with } \\
\text { high popularity }\end{array}$ & $\begin{array}{l}\text { Keywords that } \\
\text { generate high } \\
\text { Return on } \\
\text { Investment (ROI) }\end{array}$ \\
\hline Measure & $\begin{array}{l}\text { Number of } \\
\text { website visitors } \\
\text { pages }\end{array}$ & $\begin{array}{l}\text { Number } \\
\text { successfully } \\
\text { converted goals. }\end{array}$ \\
\hline $\begin{array}{l}\text { SEO pages are } \\
\text { content-heavy } \\
\text { and informative, } \\
\text { designed to use } \\
\text { keywords and } \\
\text { subject relevance } \\
\text { to rank well on } \\
\text { any search } \\
\text { engine. }\end{array}$ & $\begin{array}{l}\text { It generally leads to } \\
\text { lirect, } \\
\text { landing pages with } \\
\text { an obvious call to } \\
\text { action and designed } \\
\text { to capture sales. }\end{array}$ \\
\hline Pkill \\
Prequired
\end{tabular}

field. It requires to know about intent of the user's query. In order to perform the keyword analysis or research, we should be aware of various keyword research SEO tools. A keyword analysis is performed by identifying the popular keywords that matches with the content of the website based on its relevance and potential conversion rate and then building the website with the targeted keywords. The keywords should be monitored and updated frequently to reflect evolving best practices of SEO techniques. It is used to find alternative terms that user's enter in search engine. Each search engines provides their own keyword suggestion SEO tools. Using the search engine information about the popular keyword, the website developer can built the website with the keywords which have highest value and the highest ROI, in turn benefit the website developer to successfully position their site in top of the SERP of the search engine. It has been found that searching for keyword with low competition and still high number of searches results in higher web traffic. [2]

\section{Usage Of Seo Tools}

SEMrush provides software to generate competitive research SEO tools and reports from Google SERPs. The commonly used phrase "Online Shopping" was chosen based on the keyword analytics report collected from the
Keyword Research SEO tool in the website SEMrush.com which is shown in the Figure 1. For the search query "Online shopping sites in India" in Google search engine, we obtained the www.myntra.com website in the top result of first result page, www.amazon.in website in the third result page and www.nautica.com in the last result page.

\begin{tabular}{|c|c|c|c|c|c|c|}
\hline Keyord & Volume & 10 & $\operatorname{CPC}($ USO) & Com. & Result & Irend \\
\hline online stopoping & 49,500 & 85.25 & 1.98 & 0.84 & $558,000,000$ & \\
\hline walmart online shoopping & 33,100 & 97.91 & 0.43 & 0.55 & $5,390,000$ & |m|l|| \\
\hline onlline shopoing sittes & 14,800 & 88.56 & 1.82 & 0.74 & 139,000000 & \\
\hline online goceryshoopoing & 9900 & 81.82 & 2.24 & 0.75 & 168000000 & \\
\hline
\end{tabular}

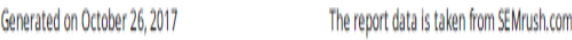

Figure 1: Keyword Analytics report from SEMrush.com

The SmallSEOTools is one of the biggest free SEO tools provider. Keyword density is the percentage of times a keyword or phrase appears on a web page compared to the total number of words on the page. Keyword density play a vital role in impacting SEO of the websites. As per Keyword density report of Mynthra in Figure 2, both "shopping" and "online" is available in the top 3 single keyword and "online shopping" is available in the first among the top 3 double keyword. As per Keyword density report of Amazon in Figure 3, "shop" is available in the top 3 single keyword and "shop online" is available twice in top 3 triple keyword. As per Keyword density report of Nautica in Figure 2, "shop" is available in the top 3 single keyword and "shop" is available in top 3 double keyword. The keyword density report helps us to relate the reason for being www.myntra.com in the top result of first result page, www.amazon.in website in the third result page and www.nautica.com in the last result page of Google search engine for the keyword phrase "Online shopping sites in India". The website should be carefully designed and coded with various SEO friendly techniques [6].

The factors that impacts the SEO of the website is depicted in the Table 2 and described in detail below:

- Length of the page title should be less than 65 characters.

- Length of the Meta description length should be less than 165 characters. 


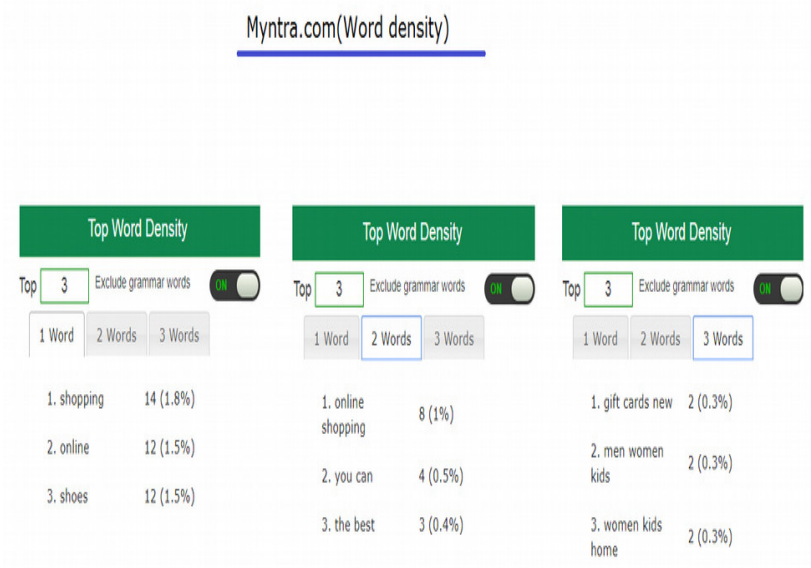

Figure 2: Keyword Density report of Mynthra from SmallSEOtools.com

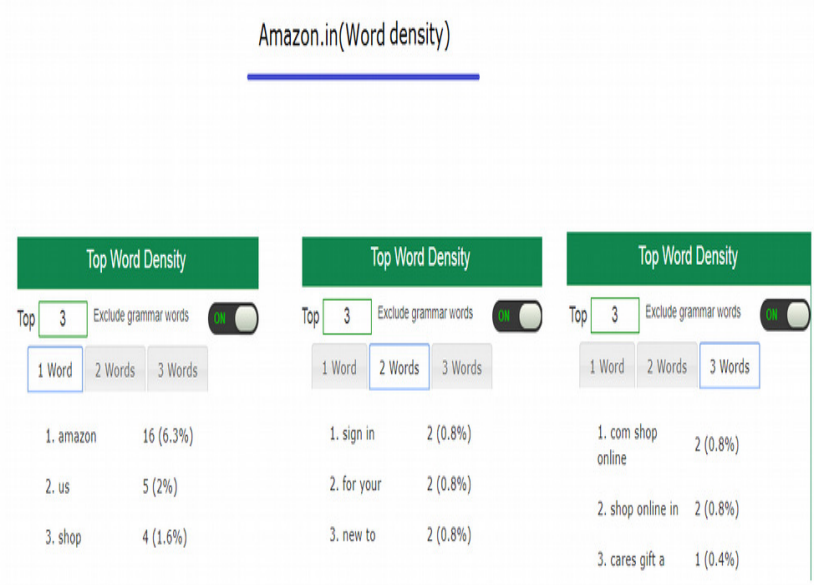

Figure 3: Keyword Density report of Amazon from SmallSEOtools.com

Nautica.com(word density)
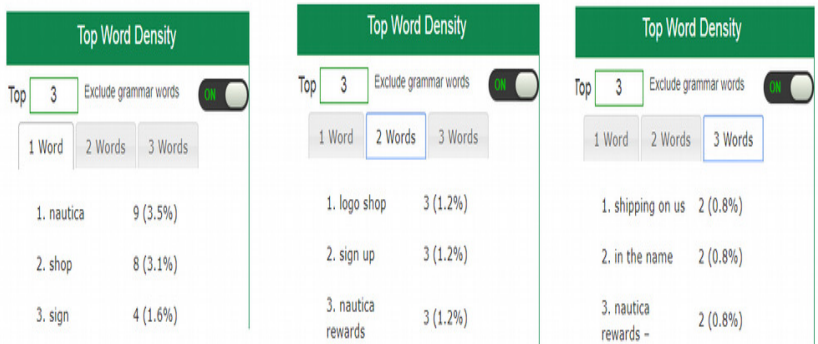

Figure 4: Keyword Density report of Nautica from SmallSEOtools.com
- Primary keywords should appear in Meta Keywords which helps search engine to identify the website's topic.

- Absence of H1 and H2 headings highly effects page SEO.

- $\quad$ Site should have SITEMAPS.

- HyperLinks should not be broken .

- There should be no underscore's in site's in-page URL's.

- All image tags should have attribute ALT.

- $\quad$ Page should not use HTML Deprecated tags.

- Absence of noindex tag allows the webpage to be read and indexed by search engines

- Absence of nofollow tag allows the links of the webpage to be crawled by search engines.

- Web page size should be less than $33 \mathrm{~kb}$ which will decrease the loading time of the web page.

Table 2: Website SEO Score Checker report from SmallSEOtools.com

\begin{tabular}{|l|l|l|l|}
\hline CRITERIA & MYNTHRA & AMAZON & NAUTICA \\
\hline Page Title & Yes & Yes & Yes \\
\hline $\begin{array}{l}\text { Meta } \\
\text { Description }\end{array}$ & Yes & Yes & Yes \\
\hline Meta Keyword & Yes & Yes & Yes \\
\hline H1 Heading & No & Yes & No \\
\hline H2 Heading & Yes & No & Yes \\
\hline Robot.txt file & No & Yes & Yes \\
\hline Sitemap & No & No & Yes \\
\hline Broken Link & No & No & No \\
\hline $\begin{array}{l}\text { SEO Friendly } \\
\text { Url }\end{array}$ & Yes & No & No \\
\hline $\begin{array}{l}\text { Img Alt } \\
\text { attribute }\end{array}$ & No & Yes & Yes \\
\hline $\begin{array}{l}\text { Deprecated } \\
\text { HTML }\end{array}$ & Yes & Yes & Yes \\
\hline NoIndex tag & Yes & Yes & Yes \\
\hline NoFollow tag & Yes & Yes & Yes \\
\hline $\begin{array}{l}\text { WWW } \\
\text { redirection }\end{array}$ & Yes & Yes & Yes \\
\hline Page Size test & Yes & No & Yes \\
\hline $\begin{array}{l}\text { Compression } \\
\text { test }\end{array}$ & Yes & Yes & Yes \\
\hline
\end{tabular}

\section{Conclusion}

The website developer should be aware of various SEO techniques that gradually ensures the highly relevant content-rich website is placed in the top ranked result pages of the search engine. The comparison study of SEM and SEO help us to understand the marketing and technical aspect of the website in the digital marketing. The Keyword analysis illustrates that it plays a vital role in the prevailing SEO techniques. The Crawled texts \& links, Indexed pages and the Keyword density of the website can be monitored using 
advanced SEO tools and provide the SEO report on daily or weekly or monthly basis which helps to improve the traffic of the website and the overall sales of the product or services.

\section{ACKNOWLEDGEMENTS}

We would like to acknowledge this research paper to our teachers of our department and our family for their constant support and inspiration.

\section{REFERENCES}

[1] D. M. Patil, K. M. Jadhav, M. G. Patil, "A study on Search engine an Search Engine Optimization", International Journal of Advance Research in Computer Science and Management Studies, Vol. 3, Issue 6,2015 .
[2] M. Bansal, D. Sharma, "Improving Webpage Visibility in Search Engines by Enhancing Keyword Density Using Improved On-Page Optimization Technique", International Journal of Computer Science and Information Technologies, Vol. 6, Issue 6, 2015.

[3] K. Samrat, "Concept of Search Engine Optimization in Web Search Engine", International Journal of Advanced Engineering Research and Studies, Vol. 1, Issue 1, 2011.

[4] S. Gupta, N. Agrawal, S. Gupta, "A Review on Search Engine Optimization: Basics", International Journal of Hybrid Information Technology, Vol. 9, Issue 5, 2016.

[5] L. Zhang, J. Zhang, Y. Ju, "The Research on Search Engine Optimization Based on Six Sigma Management", IEEE International Conference on E-Business and E-Government (ICEE), 2011.

[6] A. R. Terrance, "Search Engine Optimization - A critical element in Digital Marketing", National Seminar Proceedings of a paradigm shift towards Empowerment of Women, 2017 